\title{
Patterns of complex emergency general surgery in Canada
}

\author{
Kelly N. Vogt, MD, MSc \\ Laura Allen, MSc \\ Patrick B. Murphy, MD, MSc \\ Rardi van Heest, MD \\ Fady Saleh, MD \\ Sandy Widder, MD, MSc \\ Sam Minor, MD \\ Paul T. Engels, MD \\ Emilie Joos, MD \\ Rahima Nenshi, MD \\ Michael T. Meschino, MD \\ Charlotte Laane, MD \\ Ayush Lacoul, MD \\ Neil G. Parry, MD \\ Chad G. Ball, MD, MSc \\ S. Morad Hameed, MD, MPH
}

Presented at the Canadian Surgery Forum, Sept. 14-16, 2017, Victoria, B.C.

Accepted Oct. 24, 2019

\section{Correspondence to: \\ K. Vogt \\ London Health Sciences Centre \\ Victoria Hospital \\ 800 Commissioners Rd E \\ London ON N6A 5W9 \\ kelly.vogt@Ihsc.on.ca}

DOI: $10.1503 /$ cjs.011219
Background: Most of the literature on emergency general surgery (EGS) has investigated appendiceal and biliary disease; however, EGS surgeons manage many other complex conditions. This study aimed to describe the operative burden of these conditions throughout Canada.

Methods: This multicentre retrospective cohort study evaluated EGS patients at 7 centres across Canada in 2014. Adult patients (aged $\geq 18 \mathrm{yr}$ ) undergoing nonelective operative interventions for nonbiliary, nonappendiceal diseases were included. Data collected included information on patients' demographic characteristics, diagnosis, procedure details, complications and hospital length of stay. Logistic regression was used to identify predictors of morbidity and mortality.

Results: A total of 2595 patients were included, with a median age of 60 years (interquartile range 46-73 yr). The most common principal diagnoses were small bowel obstruction (16\%), hernia (15\%), malignancy $(11 \%)$ and perianal disease $(9 \%)$. The most commonly performed procedures were bowel resection $(30 \%)$, hernia repair (15\%), adhesiolysis (11\%) and débridement of skin and soft tissue infections (10\%). A total of $47 \%$ of cases were completed overnight (between $5 \mathrm{pm}$ and $8 \mathrm{am}$ ). The overall inhospital mortality rate was $8 \%$. Thirty-three percent of patients had a complication, with independent predictors including increasing age $(p=0.001)$, increasing American Society of Anesthesiologists score $(p=0.02)$ and transfer from another centre $(p=0.001)$.

Conclusion: This study characterizes the epidemiology of nonbiliary, nonappendiceal EGS operative interventions across Canada. Canadian surgeons are performing a large volume of EGS, and conditions treated by EGS services are associated with a substantial risk of morbidity and mortality. Results of this study will be used to guide future research efforts and set benchmarks for quality improvement.

Contexte : La plupart des études sur les services de chirurgie générale d'urgence (CGU) s'intéressent seulement aux atteintes de l'appendice et de la vésicule biliaire. Pourtant, les chirurgiens du domaine traitent beaucoup d'autres problèmes complexes. L'objectif de l'étude était de décrire le travail chirurgical associé à ces problèmes dans l'ensemble du Canada.

Méthodes : Notre étude de cohorte rétrospective multicentrique inclut les patients adultes ( $\geq 18$ ans) qui ont subi en 2014 une opération non planifiée pour une atteinte qui ne touchait ni l'appendice ni la vésicule biliaire dans 1 des 7 centres sélectionnés, répartis un peu partout au pays. Nous avons recueilli les données suivantes : renseignements de base des patients, diagnostic, détails de l'intervention, nature des complications et durée d'hospitalisation. Puis nous avons dégagé les facteurs prédictifs de morbidité et de mortalité en appliquant un modèle de régression logistique.

Résultats : L'échantillon totalisait 2595 patients, pour un âge médian de 60 ans (écart interquartile 46-73 ans). Les diagnostics principaux les plus courants étaient l'occlusion de l'intestin grêle (16\%), la hernie (15\%), la tumeur maligne $(11 \%)$ et les lésions périanales (9\%). Les interventions les plus fréquentes étaient la résection de l'intestin $(30 \%)$, la réparation d'une hernie $(15 \%)$, le débridement $(11 \%)$ et le débridement de tissus mous ou cutanés infectés (10\%). L'opération a eu lieu le soir ou la nuit (entre $17 \mathrm{~h}$ et $8 \mathrm{~h}$ ) dans $47 \%$ des cas. Le taux global de mortalité à l'hôpital était de $8 \%$. Des complications sont survenues chez $33 \%$ des patients, dont les facteurs prédictifs indépendants étaient l'âge avancé ( $p=0,001)$, un score ASA (de l'American Society of Anesthesiologists) élevé $(p=0,02)$ et le transfert à partir d'un autre centre $(p=0,001)$.

Conclusion : Cette étude dresse le profil épidémiologique des interventions effectuées par les services de CGU du Canada en présence d'atteintes autres que celles de l'appendice et de la vésicule biliaire. Les chirurgiens du pays font beaucoup d'interventions générales urgentes, pour traiter des affections associées à un risque élevé de morbidité et de mortalité. Les résultats de l'étude guideront les prochaines recherches et serviront de points de référence en matière d'amélioration de la qualité. 
$\mathrm{E}$ mergency general surgery (EGS) is associated with a tremendous burden of disease. In the United States, EGS admissions represent 7\% of all hospital admissions, and in 2010 they cost the US health care system $\$ 28.4$ billion. ${ }^{1}$ The range of conditions treated in EGS practice is diverse. Emergency general surgery itself is an independent risk factor for morbidity and mortality; EGS patients are up to 5 times more likely to die than their counterparts who undergo elective surgery, a risk not fully explained by pre- or perioperative risk factors. ${ }^{2}$

The acute care surgery (ACS) model attempts to recognize EGS as a unique entity, and patients presenting with acute surgical conditions benefit from structured care and systems. ${ }^{3-5}$ Similar to the development of trauma systems throughout the world, the development of ACS models focuses on the acute care of surgical patients within the framework of a system dedicated to emergency care. In 2009, the Canadian Association of General Surgeons held a full-day summit to define the emerging model of ACS, endorsing the term as the best descriptor of the initiative in Canada. ${ }^{6}$ There are many perceived benefits of ACS: better continuity of patient care, increased "patient ownership" for a population of patients whose care has historically been fragmented, and improved access to emergency surgical care, which is thought to improve outcomes for both individual patients and the health care system. Much of the early work on the impact of ACS models has focused on appendicitis and biliary disease. Retrospective studies published around the world have demonstrated improved outcomes both for patients presenting with these disease processes and for the health care systems to which they present. ${ }^{3,4,7}$

We know, however, that EGS goes far beyond the treatment of appendicitis and biliary pathology. There are far fewer comparative data available on the burden and outcomes of other EGS conditions. We undertook this study to describe the current burden of nonbiliary, nonappendiceal EGS conditions managed operatively on ACS services across Canada, as a first step in developing a framework for comparative research extending beyond the appendix and biliary pathology.

\section{Methods}

This multicentre retrospective cohort study evaluated patients who underwent operations on ACS services at 7 centres across Canada (University of Alberta Hospital in Edmonton, Alberta; Queen Elizabeth II Health Sciences Centre in Halifax, Nova Scotia; Hamilton Health Sciences and St. Joseph's Healthcare Hamilton in Hamilton, Ontario; London Health Sciences Centre in London, Ontario; Vancouver General Hospital in Vancouver, British Columbia; and William Osler Health System in Brampton and Etobicoke, Ontario) from Jan. 1 to Dec. 31, 2014. All adult patients ( $\geq 18 \mathrm{yr}$ ) undergoing urgent or emergent operative intervention for nonbiliary, nonappendiceal diseases were identified for inclusion. Patients were identified either from local operating room (OR) databases or through health records with a query using relevant International Classification of Diseases, 9th revision (ICD-9) and International Classification of Diseases and Related Health Problems, 10th revision (ICD-10) diagnostic codes. Characteristics of the ACS services at each centre at the time of the study can be found in Appendix 1 (Supplementary Table S1, available at canjsurg.ca/011219-a1).

Detailed chart review (electronic or paper or both) was completed for each included patient by clinical staff (attending physicians or surgical trainees) at each site. A comprehensive data collection protocol was provided to each site with standardized definitions as outlined below. Data collected included information on patients' demographic characteristics, diagnosis, procedure(s), in-hospital complications, in-hospital mortality, intensive care unit stay, hospital length of stay and 30-day readmission to the same institution. The primary outcome was the frequency of operative interventions for nonbiliary, nonappendiceal EGS conditions. We also described demographic characteristics and baseline comorbidities, along with details on operative interventions including indication, urgency of operative booking, time of day and American Society of Anesthesiologists (ASA) score (as documented in the operative record). Across Canada, centres use different time cut-offs to assess the urgency of operative intervention (i.e., booking priority); however, for the purposes of these analyses the booking priority identified from the OR database or booking form was standardized to within 2 hours, within 8 hours, within 24 hours and within 48 hours. Complications were classified using the Clavien-Dindo system (Appendix 1, Supplementary Table S2).

No sample size calculations were completed; however, before beginning this study we established a convenience sample of at least 200 patients per participating site. All centres received institutional ethics board approval before commencement of the study. Continuous parameters are expressed as means with standard deviations and medians with interquartile ranges (IQRs), as appropriate. Categorical data are expressed as proportions. Univariate analyses were conducted using the Student $t$ test for continuous, normally distributed variables; the Mann-Whitney $U$ test for continuous, nonnormally distributed variables; and the $\chi^{2}$ test for categorical variables. To identify risk factors for mortbidity and mortality, we compared demographic and interventionrelated variables for patients who experienced a complication versus those who did not and for patients who survived versus those who died. Logistic regression was used in an explanatory model to identify risk factors for both in-hospital complication and mortality, with variables for inclusion chosen on the basis of known potential for confounding. Data were analyzed using SPSS version 23 (IBM Inc.), with a $p$ value of less than 0.05 considered significant. 


\section{Results}

A total of 2595 patients who underwent nonbiliary, nonappendiceal operative intervention by the ACS service of the 7 participating centres were included in the study cohort. Individual sites contributed between 208 patients ( $8 \%$ of the total sample) and 704 patients (27\% of the total sample), and cases were performed by 90 different Canadian surgeons. The median patient age was 60 years (IQR 46-73 yr), and $51 \%$ were men (Table 1). Overall, 176 patients $(7 \%)$ underwent an operation after being transferred from another centre. Of these, $15 \%$ had an operation before transfer.

Almost half $(49 \%)$ of patients $(n=1282)$ had at least 1 comorbidity documented. The most common comorbidities were hypertension $(n=639,25 \%)$, diabetes $(n=352$, $14 \%)$ and coronary artery disease $(n=188,7 \%)$. Of note, 159 patients $(6 \%)$ had metastatic cancer at the time of their operative intervention. Further, 296 (11\%) were recorded to be current smokers at the time of presentation. The ASA score of patients at the time of first operation is listed in Table 1; the majority of patients were assigned to ASA class $3(n=779,30 \%)$ or $4(n=582,22 \%)$.

Table 2 outlines the primary diagnosis of the study patients. The most common diagnosis was small bowel obstruction $(n=403,16 \%)$, followed by hernia $(n=389$, $14 \%)$, colonic neoplasm $(n=238,9 \%)$ and perianal abscess $(n=221,8.5 \%)$. Table 3 outlines the procedures performed in accordance with these diagnoses at the time of first operation. Of note, 585 patients had an initial operative plan of exploration (laparoscopy in 105 patients [4\%]; laparotomy in 480 patients [19\%]), and in 98 cases the operation was nontherapeutic.

\begin{tabular}{|lc|}
\hline $\begin{array}{l}\text { Table 1. Patient characteristics } \\
\text { Characteristic }\end{array}$ & $\begin{array}{c}\text { No) of patients* } \\
n=2595\end{array}$ \\
\hline Age, yr, median (IQR) & $60(46-73)$ \\
\hline Sex, male & $1324(51)$ \\
\hline Comorbidities & $352(14)$ \\
\hline Diabetes & $85(3)$ \\
\hline Congestive heart failure & $188(7)$ \\
\hline Coronary artery disease & $639(25)$ \\
\hline Hypertension & $54(2)$ \\
\hline Current dialysis & $41(2)$ \\
\hline Cirrhosis & $159(6)$ \\
\hline Metastatic cancer & $296(11)$ \\
\hline Current smoker & $143(6)$ \\
\hline ASA classification at first surgery & $464(18)$ \\
\hline 1 & $779(30)$ \\
\hline 2 & $582(22)$ \\
\hline 3 & $94(4)$ \\
\hline 4 & interquartile \\
\hline 5 & \\
\hline $\begin{array}{l}\text { ASA Anless indicated otherwise. } \\
\text { range. }\end{array}$ & \\
\hline
\end{tabular}

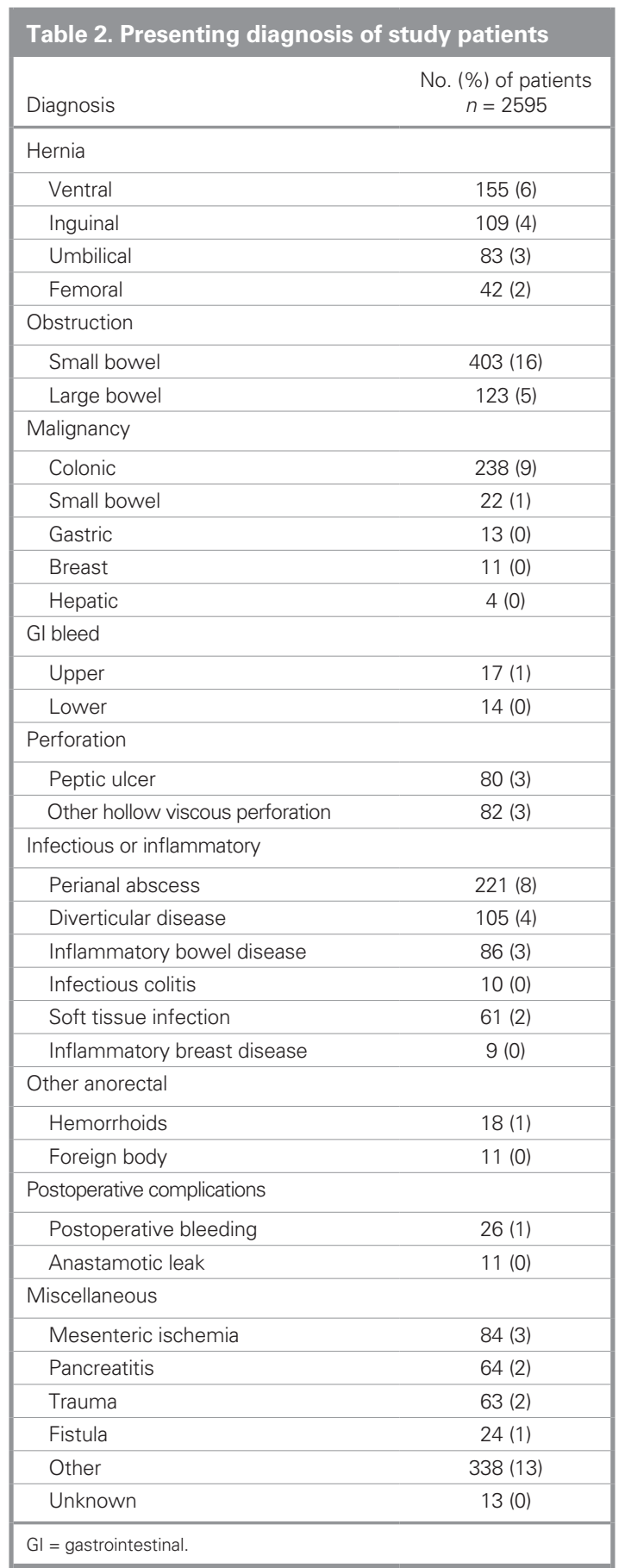

Table 4 outlines the urgency of the initial operation, on the basis of booking priority. In $47 \%$ of cases (1153 of the 2465 cases with data) the operation was performed after hours (between $5 \mathrm{pm}$ and $8 \mathrm{am}$ ). In 262 patients (10\%), a second operation was performed. Just over $3 \%$ of the study population $(n=80)$ had 3 or more operations during admission.

One-third of patients in the study cohort experienced a complication ( $n=866,33 \%)$. Among the 563 patients for whom the complication was classified, $100(12 \%)$ had a Clavien-Dindo grade 1 complication, 147 (17\%) had a 


\begin{tabular}{|c|c|}
\hline Procedure & $\begin{array}{c}\text { No. (\%) of patients* } \\
n=2595\end{array}$ \\
\hline Hernia repair & $389(15)$ \\
\hline \multicolumn{2}{|l|}{ Type } \\
\hline Inguinal & $94(24)$ \\
\hline Umbilical & $84(22)$ \\
\hline Ventral & $140(36)$ \\
\hline Femoral & $40(10)$ \\
\hline Multiple hernias & $9(2)$ \\
\hline Type not specified & $22(6)$ \\
\hline Mesh repair & $333(86)$ \\
\hline Biologic & $21(6)$ \\
\hline Nonbiologic & $177(53)$ \\
\hline Unknown & $56(17)$ \\
\hline Adhesiolysis & $288(11)$ \\
\hline Bowel resection & $789(30)$ \\
\hline \multicolumn{2}{|l|}{ Section of bowel resected } \\
\hline Small bowel & $242(31)$ \\
\hline Colon & $476(60)$ \\
\hline Small bowel and colon & $71(9)$ \\
\hline Stoma created & $254(32)$ \\
\hline Ileostomy & $140(55)$ \\
\hline Colostomy & $114(45)$ \\
\hline Ostomy creation (no resection) & $135(5)$ \\
\hline Repair of ulcer & $74(3)$ \\
\hline Graham patch & $34(46)$ \\
\hline Primary repair & $8(11)$ \\
\hline Resection & $4(5)$ \\
\hline Other & 2 (3) \\
\hline Type not specified & $26(35)$ \\
\hline Gastric resection & $24(1)$ \\
\hline Bilroth1/ 2 & $12(50)$ \\
\hline Roux-en-y & $2(8)$ \\
\hline Type not specified & $10(42)$ \\
\hline Feeding tube & $34(1)$ \\
\hline Gastrojejunostomy & $21(63)$ \\
\hline Débridement of skin and soft tissue infections & $267(10)$ \\
\hline Extremity & $5(2)$ \\
\hline Perianal & $177(66)$ \\
\hline Breast & $14(5)$ \\
\hline Abdominal wall & $54(20)$ \\
\hline Chest wall & $3(1)$ \\
\hline Other & $14(5)$ \\
\hline Trauma laparotomy & $95(3)$ \\
\hline Exploration (no additional procedure) & $98(4)$ \\
\hline
\end{tabular}

Table 4. Booking urgency of the first operation for all study patients

\begin{tabular}{|lc|} 
Urgency & $\begin{array}{c}\text { No. (\%) of patients } \\
n=2595\end{array}$ \\
\hline$<2 \mathrm{~h}$ & $376(15)$ \\
\hline $2-8 \mathrm{~h}$ & $882(34)$ \\
\hline$<24 \mathrm{~h}$ & $542(21)$ \\
\hline$<48 \mathrm{~h}$ & $341(13)$ \\
\hline Not recorded & $454(18)$ \\
\hline
\end{tabular}

Table 5. Results of univariate analysis comparing patients who did and did not experience a complication

\begin{tabular}{|c|c|c|c|}
\hline \multirow[b]{2}{*}{ Variable } & \multicolumn{2}{|c|}{ No. (\%) of patients* } & \multirow[b]{2}{*}{$p$ value } \\
\hline & $\begin{array}{c}\text { Patients without } \\
\text { complications } \\
n=1729\end{array}$ & $\begin{array}{c}\text { Patients with } \\
\text { complications } \\
n=866\end{array}$ & \\
\hline Age, median (IQR), yr & $57(44-71)$ & $65(51-77)$ & $<0.001$ \\
\hline Male sex & $869(50)$ & $443(51)$ & 0.73 \\
\hline $\begin{array}{l}\text { Transfer from another } \\
\text { centre }\end{array}$ & $99(8)$ & $77(14)$ & $<0.001$ \\
\hline Any comorbidity & $814(47)$ & $468(54)$ & 0.001 \\
\hline Diabetes & $227(13)$ & $125(14)$ & 0.36 \\
\hline Congestive heart failure & $39(2)$ & $46(5)$ & $<0.001$ \\
\hline Coronary artery disease & 100(6) & $88(10)$ & $<0.001$ \\
\hline Hypertension & $391(23)$ & $248(29)$ & 0.001 \\
\hline Current dialysis & $27(2)$ & $27(3)$ & 0.009 \\
\hline Cirrhosis & $21(1)$ & $20(2)$ & 0.035 \\
\hline Metastatic cancer & $89(5)$ & $70(8)$ & 0.003 \\
\hline Current smoker & $205(12)$ & $91(11)$ & 0.31 \\
\hline $\begin{array}{l}\text { ASA score at first } \\
\text { operation, median (IQR) }\end{array}$ & $3(2-4)$ & $3(3-4)$ & $<0.001$ \\
\hline \multicolumn{4}{|l|}{ Urgency of operation, $\mathrm{h}$} \\
\hline$<2$ & $227(15)$ & $149(23)$ & $<0.001$ \\
\hline $2-8$ & $644(43)$ & $238(37)$ & - \\
\hline$<24$ & $381(25)$ & $161(25)$ & - \\
\hline$<48$ & $248(17)$ & $93(15)$ & - \\
\hline Mortality & $102(6)$ & $104(12)$ & $<0.001$ \\
\hline
\end{tabular}

grade 2 complication, 160 (18\%) had a grade 3 complication and $156(18 \%)$ had a grade 4 complication. Table 5 compares patients who did and did not experience a complication. On univariate analysis, patients who experienced a complication were noted to be older (median age $65 \mathrm{yr}$ v. $57 \mathrm{yr}, p<0.001$ ), to have more major comorbidities (congestive heart failure, coronary artery disease, hypertension, current dialysis, cirrhosis and metastatic cancer) and to have a higher ASA score at the time of their first operation than patients who did not experience a complication $(p<0.001)$. Complications were also more likely to have occurred if a patient was transferred from another centre $(8 \%$ of patients with no complication v. $14 \%$ of patients with a complication, $p<0.001$ ). Not surprisingly, patients who experienced a complication were more likely to die $(12 \%$ mortality among patients experienced a complication v. $6 \%$ among those who did not, $p<0.001)$. In the logistic regression analysis for predictors of complications, factors found to be independently associated with a risk for complication were increasing age (OR 1.01 per year, 95\% CI 1.00-1.02), higher ASA score (OR 1.17, 95\% CI 1.03-1.34) and transfer from another centre (OR 1.83, 95\% CI 1.28-2.60) (Table 6).

The median length of stay for study patients was 8 days, but there was significant variability (IQR 4-18 d). A stay in the intensive care unit was required for 


\begin{tabular}{|c|c|c|}
\hline Variable & Odds ratio $(95 \% \mathrm{Cl})$ & $p$ value \\
\hline Age & $1.01(1.00-1.02)$ & 0.001 \\
\hline Congestive heart failure & $1.45(0.84-2.52)$ & 0.18 \\
\hline Coronary artery disease & $1.19(0.80-1.76)$ & 0.39 \\
\hline Hypertension & $1.24(0.96-1.61)$ & 0.11 \\
\hline Transfer from another centre & $1.83(1.28-2.60)$ & 0.001 \\
\hline ASA score & $1.17(1.03-1.34)$ & 0.02 \\
\hline Operation urgency $<2 \mathrm{~h}^{*}$ & $1.43(0.98-2.09)$ & 0.06 \\
\hline Operation urgency $2-8 \mathrm{~h}^{*}$ & $0.97(0.70-1.35)$ & 0.89 \\
\hline Operation urgency $<24 \mathrm{~h}$ & $1.30(0.90-1.89)$ & 0.17 \\
\hline
\end{tabular}

Table 7. Results of univariate analysis comparing patients who survived and those who died in hospital

\begin{tabular}{|lccc} 
& \multicolumn{2}{c}{ No. (\%) of patients* } & \\
\cline { 2 - 3 } & $\begin{array}{c}\text { Patients who } \\
\text { survived } \\
n=2389\end{array}$ & $\begin{array}{c}\text { Patients who died } \\
\text { in hospital } \\
n=206\end{array}$ & p value \\
\hline Variable & $58(45-72)$ & $69(62-79)$ & $<0.001$ \\
\hline Age, median (IQR), yr & $1205(51)$ & $107(52)$ & 0.71 \\
\hline Male sex & $152(9)$ & $24(16)$ & 0.003 \\
\hline $\begin{array}{l}\text { Transfer from another } \\
\text { centre }\end{array}$ & $1136(48)$ & $146(71)$ & $<0.001$ \\
\hline Any comorbidity & $318(13)$ & $34(17)$ & 0.20 \\
\hline Diabetes & $66(3)$ & $19(9)$ & $<0.001$ \\
\hline Congestive heart failure & $153(6)$ & $35(17)$ & $<0.001$ \\
\hline Coronary artery disease & $568(24)$ & $71(35)$ & 0.001 \\
\hline Hypertension & $40(2)$ & $14(7)$ & $<0.001$ \\
\hline Current dialysis & $28(1)$ & $13(6)$ & $<0.001$ \\
\hline Cirrhosis & $130(5)$ & $29(14)$ & $<0.001$ \\
\hline Metastatic cancer & $262(11)$ & $34(17)$ & 0.016 \\
\hline Current smoker & $3(2-4)$ & $4(4-4)$ & $<0.001$ \\
\hline $\begin{array}{l}\text { ASA score at first } \\
\text { operation, median (IQR) }\end{array}$ & & & \\
\hline Urgency of operation, $\mathrm{h}$ & & $78(46)$ & $<0.001$ \\
\hline <2 & $298(15)$ & $63(37)$ & - \\
\hline $2-8$ & $819(42)$ & $20(12)$ & - \\
\hline$<24$ & $522(27)$ & $9(5)$ & - \\
\hline$<48$ & $332(17)$ & & \\
\hline ASA = American Society of Anesthesiologists; IOR = interquartile range. & \\
\hline *Unless indicated otherwise. & & & \\
\hline & & & \\
\hline
\end{tabular}

$361(14 \%)$ of patients, and the median length of stay in the intensive care unit was 5 days (IQR 2-14 d). Overall in-hospital mortality was $8 \%(n=206) ; 86(42 \%)$ of these patients were noted to have had life support withdrawn on the basis of the patient's previously stated wishes or the wishes of a substitute decision-maker. Table 7 compares the patients who died in hospital with those who survived. On univariate analysis, those who died in hospital were found to be older (median age 69 v. $58 \mathrm{yr}, p<$ 0.001), to have more major comorbidities (congestive heart failure, coronary artery disease, hypertension, current dialysis, cirrhosis, metastatic cancer), to have a higher ASA score at the time of initial operation (median
Table 8. Results of logistic regression analysis for in-hospital mortality

\begin{tabular}{|lcc|}
\hline Variable & Odds ratio $(95 \% \mathrm{Cl})$ & p value \\
\hline Age & $1.03(1.02-1.05)$ & $<0.001$ \\
\hline Congestive heart failure & $0.99(0.46-2.14)$ & 0.99 \\
\hline Coronary artery disease & $1.39(0.76-2.54)$ & 0.29 \\
\hline Hypertension & $0.98(0.62-1.55)$ & 0.94 \\
\hline Transfer from another centre & $1.06(0.59-1.92)$ & 0.84 \\
\hline ASA score & $3.36(2.52-4.47)$ & $<0.001$ \\
\hline Operation urgency $<2 \mathrm{~h}^{*}$ & $4.60(2.05-10.32)$ & $<0.001$ \\
\hline Operation urgency 2-8 $\mathrm{h}^{*}$ & $2.50(1.16-5.41)$ & 0.02 \\
\hline Operation urgency $<24 \mathrm{~h}$ & $1.70(0.66-4.40)$ & 0.27 \\
\hline Operation complication & $1.08(0.71-1.66)$ & 0.71 \\
\hline $\begin{array}{l}\text { ASA }=\text { American Society of Anesthesiologists; } \mathrm{Cl}=\text { confidence interval. } \\
\text { *In comparison with operation urgency }<48 \mathrm{~h} .\end{array}$ \\
\hline
\end{tabular}

4 v. $3 ; p<0.001)$ and to have a more urgent initial operation $(p<0.001)$. Patients who died were also more likely to have been transferred from another centre $(16 \% \mathrm{v}$. $9 \%, p<0.001)$. Table 8 presents the results of logistic regression analysis for predictors of mortality. Factors found to be independently associated with mortality were age (OR 1.03 per yr, 95\% CI 1.02-1.05), ASA score (OR 3.36, 95\% CI 2.52-4.47), and surgery classified as emergent $(<2$ h, OR 4.60, 95\% CI 2.05-10.32) or urgent (2-8 h, OR 2.50, 95\% CI 1.16-5.41).

\section{Discussion}

This study is the first to our knowledge to quantify the burden of nonbiliary, nonappendiceal operations performed by ACS services across Canada. In this large cohort, we demonstrate that ACS services are doing a substantial volume of EGS operations annually and that almost half of the operations are performed after hours. Emergency general surgery patients have a high burden of comorbidity before presentation, and they are classified by our anesthesiology colleagues as having severe systemic disease at the time of initial operative intervention. As such, EGS is associated with a high risk of morbidity and mortality: $33 \%$ of the patients in our study experienced operative complications and $8 \%$ died in hospital. In addition to comorbidities and severity of presenting illness, we identified transfer from another centre to be associated with an increased risk of morbidity.

Since their inception in the early 2000s, ACS services have proliferated across Canada, in line with trends seen internationally. Although research has begun to accumulate to support this change in practice, most studies have investigated the 2 most common presentations: appendicitis and acute biliary disease. The complete caseload of ACS services extends beyond these 2 common presentations, however, and therefore studies examining the other patients managed by EGS surgeons are essential to provide a framework for understanding the epidemiology, 
morbidity and mortality associated with nonbiliary, nonappendiceal conditions. ${ }^{8-10}$ These studies demonstrate operative rates in admitted patients ranging from $25 \%$ to $88 \%{ }^{3,8-10}$ In all series, the most frequently performed operations are appendectomy and cholecystectomy. Similar to our results, however, the remainder of the cases can be categorized as hernia repairs, bowel resections for benign and malignant disease, and drainage of skin and soft tissue infections. Our group recently published a national study describing the complete caseload of ACS services across Canada in a single day and demonstrated similar rates of operative intervention ( $51 \%$ of cases) with biliary disease, intestinal obstruction and appendiceal disease being the most common diagnoses. ${ }^{12}$

Although it was not the objective of the studies outlined above to describe details of the operative interventions performed on ACS services, this remains a substantial gap in the literature. Our study contributes further details on operative interventions beyond appendectomy and cholecystectomy. A substantial proportion of patients underwent urgent repair of hernias, management of bowel obstructions and intestinal perforations and operative management of malignancy. Less common but potentially more complex cases included gastric resections, creation of gastrojejunostomies and trauma laparotomies. The breadth of operative interventions described here underscores the need for comprehensive training programs to produce the next generation of ACS surgeons capable of managing the variety of pathologies presented. This is increasingly important as surgery becomes more subspecialized.

Our study also provides a greater evaluation of the morbidity and mortality associated with these operations. It is clear that ACS services are operating on patients who have medically complex needs, as assessed by the presence of comorbidities, the urgency with which these cases are booked and the assigned ASA scores at the time of operation. Further, half of operations occur after hours. It is not unexpected that rates of morbidity and mortality are high in this patient population. The fact that one-third of patients undergoing operative intervention will have a complication, however, demonstrates the immense opportunity for quality improvement as cohesive and specialized ACS services develop and variation in care is reduced. Key predictors of both morbidity and mortality include advancing age, comorbidity and a greater degree of physiologic derangement at the time of operation. Our finding that patient transfer from another centre is an independent risk factor for morbidity is of interest and deserves further exploration. These findings provide targets for specialized ACS services to address in attempts to minimize morbidity and mortality in our EGS patients who are sick and have complex needs, and they have implications for regionalization of ACS services. Specifically, we suggest that this patient population must be looked at systematically and critically within health care systems, with an eye to reducing rates of morbidity associated with these EGS procedures.

\section{Limitations}

Although this is a large study spanning Canada, it is limited by its retrospective nature and the inclusion only of operative data. The main limitation in the data presented here is the variability in operative booking priorities between sites. Although data collection was standardized as described above, the categories used in the study did not match directly with the booking priority options at each study site. Although we anticipate the impact of these discrepancies to be minor, they are worth consideration.

\section{Conclusion}

This study describes the current epidemiology of complex operative interventions performed by ACS services across Canada. The burden of EGS continues to be great, with high morbidity and mortality rates. It is essential to understand the current operative interventions and outcomes to allow for future benchmarking to improve quality of care, and future work should focus on these objectives.

Affiliations: From the Division of General Surgery, Department of Surgery, Schulich School of Medicine \& Dentistry, University of Western Ontario, London, Ont. (Vogt, Allen, Murphy, Parry); the Division of General Surgery, Department of Surgery, William Osler Health System, Brampton, Ont. (Van Heest, Saleh); the Division of General Surgery, Department of Surgery, University of Alberta, Edmonton, Alta. (Widder); the Divisions of General Surgery and Critical Care Medicine, Queen Elizabeth II Health Sciences Centre, Dalhousie University, Halifax, N.S. (Minor, Lacoul); the Department of Surgery Hamilton General Hospital, McMaster University, Hamilton, Ont. (Engels, Nenshi, Meschino); the Division of Trauma and Acute Care Surgery, Vancouver General Hospital, University of British Columbia, Vancouver, B.C. (Joos, Laane, Hameed); and the Divisions of Surgery and Oncology, University of Calgary, Calgary, Alta. (Ball).

Competing interests: C. Ball is co-editor in chief, and K. Vogt and S. Widder are associate editors of CJS; they were not involved in the review or decision to accept this manuscript for publication. No other competing interests were declared.

Contributors: K. Vogt, L. Allen, P. Murphy, P. Engels, N. Parry, C. Ball and M. Hameed designed the study. K. Vogt, L. Allen, P. Murphy, R. van Heest, F. Saleh, S. Widder, S. Minor, P. Engels, E. Joos, R. Nenshi, M. Meschino, C. Laane, A. Lacoul and C. Ball acquired the data, which K. Vogt, L. Allen, P. Murphy, R. van Heest, C. Ball and M. Hameed analyzed. K. Vogt, L. Allen and P. Murphy wrote the manuscript, which L. Allen, P. Murphy, R. van Heest, F. Saleh, S. Widder, S. Minor, P. Engels, E. Joos, R. Nenshi, M. Meschino, C. Laane, A. Lacoul, N. Parry, C. Ball and M. Hameed critically reviewed. All authors approved the final version of the article to be published.

\section{References}

1. Gale SC, Shafi S, Dombrovskiy VY, et al. The public health burden of emergency general surgery in the United States: a 10-year analysis of the Nationwide Inpatient Sample - 2001 to 2010. 7 Trauma Acute Care Surg 2014;77:202-8. 
2. Havens JM, Peetz AB, Do WS, et al. The excess morbidity and mortality of emergency general surgery. 7 Trauma Acute Care Surg 2015;78:306-11.

3. Murphy PB, DeGirolamo K, Van Zyl TJ, et al. Meta-analysis on the impact of the acute care surgery model of disease- and patientspecific outcomes in appendicitis and biliary disease. 7 Am Coll Surg 2017;225:763-777.e13.

4. DeGirolamo K, Murphy PB, D'Souza K, et al. Processes of health care delivery, education, and provider satisfaction in acute care surgery: a systematic review. Am Surg 2017;83:1438-46.

5. To KB, Kamdar NS, Patil P, et al. Acute care surgery model and outcomes in emergency general surgery. 7 Am Coll Surg 2019;228:21-8.

6. Hameed SM, Brenneman FD, Ball CG, et al. General surgery 2.0: the emergence of acute care surgery in Canada. Can 7 Surg 2010;53:79-83.

7. Britt RC, Bouchard C, Weireter LJ, et al. Impact of acute care surgery on biliary disease. 7 Am Coll Surg 2010;210:595-9.
8. Ramsay G, Wohlgemut JM, Jansen JO. Emergency general surgery in the United Kingdom: a lot of general, not many emergencies, and not much surgery. 7 Trauma Acute Care Surg 2018;85:500-6.

9. Cherry-Bukowiec JR, Miller BS, Doherty GM, et al. Nontrauma emergency surgery: optimal case mix for general surgery and acute care surgery training. 7 Trauma 2011;71:1422-6.

10. van Zyl TJ, Murphy PB, Allen L, et al. Beyond just the operating room: characterizing the complete caseload of a tertiary acute care surgery service. Can 7 Surg 2018;61:7417.

11. Dindo D, Demartines N, Clavien PA, et al. Classification of surgical complications: a new proposal with evaluation in a cohort of 6336 patients and results of a survey. Ann Surg 2004;240:205-13.

12. DeGirolamo K, D'Souza K, Apte S, et al. A day in the life of emergency general surgery in Canada: a multicentre observational study. Can 7 Surg 2018;61:237-43. 